\title{
Correction to: Biodegradation of naphthenic acids: identification of Rhodococcus opacus R7 genes as molecular markers for environmental monitoring and their application in slurry microcosms
}

\author{
J. Zampolli ${ }^{1}$ - A. Di Canito ${ }^{1}$ - M. Cappelletti ${ }^{2} \cdot$ E. Collina $^{3} \cdot$ M. Lasagni $^{3} \cdot$ P. Di Gennaro ${ }^{1}$ \\ Published online: 11 February 2020 \\ (C) Springer-Verlag GmbH Germany, part of Springer Nature 2020
}

Correction to: Applied Microbiology and Biotechnology https://doi.org/10.1007/s00253-020-10378-5

The published online version contains mistake in the author list for the author "M. Cappelletti" was incorrectly presented. Incorrect name:

\section{Capelletti}

The correct presentation is now given above.

The original article has been corrected.

The online version of the original article can be found at https://oi.org/ $10.1007 / \mathrm{s} 00253-020-10378-5$

\footnotetext{
P. Di Gennaro

patrizia.digennaro@unimib.it

1 Department of Biotechnology and Biosciences, University of Milano-Bicocca, Piazza della Scienza 2, 20126 Milan, Italy

2 Department of Pharmacy and Biotechnology, University of Bologna, Via Irnerio 42, 40126 Bologna, Italy

3 Department of Earth and Environmental Sciences, University of Milano-Bicocca, Piazza della Scienza 1, 20126 Milan, Italy
} 